Article

\title{
The Synthesis of YNU-5 Zeolite and Its Application to the Catalysis in the Dimethyl Ether-to-Olefin Reaction
}

\author{
Qing Liu, Yuka Yoshida, Naoto Nakazawa, Satoshi Inagaki $\mathbb{D}$ and Yoshihiro Kubota *(D) \\ Division of Materials Science and Chemical Engineering, Yokohama National University, \\ Yokohama 240-8501, Japan \\ * Correspondence: kubota-yoshihiro-sr@ynu.ac.jp
}

Received: 24 March 2020; Accepted: 23 April 2020; Published: 26 April 2020

check for updates

\begin{abstract}
During prior investigations of the synthesis of the novel zeolite YNU-5 (YFI), it was found that a very slight amount of an impurity phase contaminated the desired zeolitic phase. This impurity was very often ZSM-5 (MFI). The phase composition was determined to be sensitive to the water in the synthesis mixture, and it was possible to obtain a pure phase and also to intentionally generate a specific impurity phase. In the present work, trials based on the dimethyl ether-to-olefin (DTO) reaction using a fixed-bed downflow reactor were performed to assess the effect of the purity of YNU-5 on its catalytic performance. Dealuminated pure YNU-5 exhibited rapid deactivation due to coking at time on stream (TOS) values exceeding $5 \mathrm{~min}$. Surprisingly, this deactivation was greatly suppressed when the material contained a trace amount of ZSM-5 consisting of nano-sized particles. The formation of ZSM-5 nanoparticles evidently improved the performance of the catalytic system during the DTO reaction. The product distributions obtained from this reaction using highly dealuminated and very pure YNU-5 resembled those generated by 12-ring rather than 8-ring zeolite catalysts. The high selectivity for desirable $\mathrm{C} 3$ and $\mathrm{C} 4$ olefins during the DTO reaction over YNU-5 is beneficial.
\end{abstract}

Keywords: zeolite; YNU-5; solid acid catalyst; DTO reaction

\section{Introduction}

Zeolites are crystalline aluminosilicates that possess an exceptional combination of properties, including high thermal stability, Brønsted acidity, and microporosity, due to their well-defined channel systems [1,2]. These materials have been used in a diverse range of applications, including as ion exchangers, adsorbents, and catalysts for many refining and petrochemical processes [3-6]. Even though there are a variety of chemical compositions in zeolite-like materials, aluminosilicates are the most typical. Zeolites possessing a high $\mathrm{Si} / \mathrm{Al}$ ratio and a three-dimensional (3D) channel system including large pore (that is, 12-ring) channels are of particular interest, since they combine high thermal and hydrothermal stability with superior resistance to pore blockage $[7,8]$. Some examples of high-silica, large-pore microporous aluminosilicates that are especially promising on the basis of the above criteria are beta ( ${ }^{*}$ BEA) [8-13], MCM-68 (MSE), and related MSE-type materials. Another interesting example is CIT-1 (CON), which has a 12-12-10-ring pore system. This material was first synthesized as a borosilicate [14], after which the Al-containing borosilicate $\mathbf{C O N}([\mathrm{Al}, \mathrm{B}]-\mathrm{CON})$ was successfully crystallized [15]. Al-containing CON-type zeolites have exhibited excellent catalytic performance in the methanol-to-olefin (MTO) reaction because of their unique structures and their ability to promote the ready accessibility and diffusion of reactants [15-17].

Some small-pore (that is, 8-ring) zeolite frameworks such as CHA (having an 8-8-8-ring system) can also be applied to the MTO reaction, and CHA can also be used as a catalyst for the $\mathrm{NH}_{3}$-selective catalytic reduction (SCR) reaction. Very recently, our own group has found that the AFX framework 
(having an 8-8-8-ring structure) is an even more interesting catalyst for the $\mathrm{NH}_{3}$-SCR process [18]. In addition, it should be noted that mordenite (MOR) has 12-ring straight channels with intersecting 8-ring pores, and is one of the most industrially useful zeolite catalysts. It is thus expected that combinations of 12-ring and 8-ring pores will provide useful materials.

Our group has successfully synthesized the new aluminosilicate zeolite YNU-5 having a 12-12-8-ring pore system together with an independent 8-ring system, using dimethyldipropylammonium $\left(\mathrm{Me}_{2} \mathrm{Pr}_{2} \mathrm{~N}^{+}\right)$as the organic structure-directing agent (OSDA) [19]. This material was given the framework type code YFI by the International Zeolite Association (IZA) [20]. After the synthesis and structural determination of this substance, it was characterized with regard to potential catalytic applications in three respects: (1) by obtaining information regarding critical factors that affect the successful crystallization of YNU-5, (2) by establishing framework stabilization when preparing a high-silica YNU-5 catalyst, and (3) by assessing the relationship between phase purity (that is, the presence of very small amounts of an impurity phase) and catalytic performance.

Regarding issue (2), our work demonstrated that YNU-5 only crystallizes at a Si/Al ratio of approximately 9 in the product. Although dealumination was possible using a liquid phase post-synthetic treatment with nitric acid, the framework stability of this material was determined to be sensitive to the dealumination conditions. Specifically, a reflux temperature (oil-bath temperature $130^{\circ} \mathrm{C}$ rather than $80^{\circ} \mathrm{C}$ ) promoted framework stability by allowing the migration of $\mathrm{Si}$ to fill site defects generated by the removal of framework Al [21]. This simple technique for stabilizing the framework is very valuable because it guarantees the thermal and hydrothermal stability of the catalyst during use and/or regeneration. A remaining challenge that corresponds to issue (1) is that the synthesis window is very narrow, and in most cases, a very slight amount of an impurity phase contaminates the desired YNU-5 product. In our previous work [21], several competing phases, such as MCM-68 (MSE), ZSM-5 (MFI), and beta ( ${ }^{*}$ BEA), were observed following slight changes in the gel composition (especially the amount of water) during synthesis. Even after optimization of the synthesis conditions, trace amounts of MFI or MOR were frequently still observed as an impurity.

To address issue (3), we focused on the catalytic performance of YNU-5 with regard to the dimethyl ether (DME)-to-olefin (DTO) reaction. This reaction, together with the MTO reaction, is important as an alternative to the thermal cracking of ethane (supplied from nonpetroleum fossil-based resources such as natural gas or shale gas) because thermal cracking alone cannot satisfy the demand for propylene. In addition, butenes and higher molecular weight olefins are currently more in demand than ethylene. During these acid-catalyzed reactions, we found that even trace amounts of impurities in the YNU-5 catalyst greatly affected the catalytic performance, which was unexpected because this effect is not often observed. Therefore, in order to employ this material in catalytic applications, it is essential to establish how these impurities affect the performance of YNU-5.

We report here additional systematic investigations of the optimal synthetic conditions (specifically, gel composition, crystallization state, and time span) and of the effect of small concentrations of MFI impurities on the catalytic performance of YNU-5 during the DTO reaction.

\section{Materials and Methods}

\subsection{Measurements}

Powder X-ray diffraction (XRD; Ultima-IV, Rigaku, Akishima, Tokyo, Japan) data were collected using $\mathrm{Cu} \mathrm{K} \alpha$ radiation and operating at $40 \mathrm{kV}$ and $20 \mathrm{~mA}$ to examine the crystallinity and phase purity of the zeolite catalysts. The Si/Al molar ratios in the bulk materials were determined by inductively coupled plasma—atomic emission spectrometry (ICP-AES; ICPE-9000, Shimadzu Ltd., Kyoto, Japan). In preparation for these analyses, a catalyst sample ( $20 \mathrm{mg})$ was suspended in Milli-Q (Merck KGaA, Darmstadt, Germany) water ( $5 \mathrm{~g}$ ) within a Teflon beaker followed by the addition of $47 \% \mathrm{HF}(120 \mathrm{mg})$ at room temperature, ultrasonication for $2 \mathrm{~min}$ to provide dissolution, and dilution with Milli-Q water ( $90 \mathrm{~g}$ ). The crystal sizes and morphologies of the zeolite catalysts were observed 
by means of field emission scanning electron microscopy (FE-SEM; JSM-7001F, JEOL Ltd., Akishima, Tokyo, Japan). Solid-state magic angle spinning nuclear magnetic resonance (MAS NMR) data were collected using a spectrometer (AVANCEIII 600, Bruker Co., Billerica, MA, USA) operated at $600 \mathrm{MHz}$ for ${ }^{1} \mathrm{H}$ analyses and $119.2 \mathrm{MHz}$ for ${ }^{29} \mathrm{Si}$ analyses. All MAS NMR spectra were recorded at room temperature with a $4 \mathrm{~mm}$ diameter $\mathrm{ZrO}_{2}$ tube. The ${ }^{29} \mathrm{Si}$ chemical shifts were determined based on that of hexamethylcyclotrisiloxane at $-9.66 \mathrm{ppm}$. Dipolar-decoupling (DD) MAS NMR data were acquired using 1024 pulses with a recycle time of $30 \mathrm{~s}$ at a spinning rate of $10 \mathrm{kHz}$. The coke contents of the spent catalysts were determined by thermogravimetric/differential thermal analysis (TG-DTA) on a Thermo plus EVO II TG8120 (Rigaku). The temperature was raised from room temperature to $800^{\circ} \mathrm{C}$ with the rate of $10^{\circ} \mathrm{C} \cdot \mathrm{min}^{-1}$ under air flow $\left(30 \mathrm{~cm}^{3} \cdot \mathrm{min}^{-1}\right)$. The weight loss observed from 300 to $700{ }^{\circ} \mathrm{C}$ was ascribed to coke.

\subsection{Typical YNU-5 Synthesis Procedure}

The YNU-5 zeolite was typically synthesized as follows [19,21]. Initially, an aqueous $\mathrm{Me}_{2} \mathrm{Pr}_{2} \mathrm{~N}^{+} \mathrm{OH}^{-}$solution $\left(2.847 \mathrm{mmol} \cdot \mathrm{g}^{-1}, 11.94 \mathrm{~g}, 34.0 \mathrm{mmol}\right.$ ), aqueous $\mathrm{NaOH}$ solution $\left(9.048 \mathrm{mmol} \cdot \mathrm{g}^{-1}\right.$, $3.32 \mathrm{~g}$, $30.0 \mathrm{mmol})$, aqueous $\mathrm{KOH}$ solution $\left(6.075 \mathrm{mmol} \cdot \mathrm{g}^{-1}, 4.94 \mathrm{~g}, 30.0 \mathrm{mmol}\right)$, colloidal silica (21.59 g; Ludox AS-40, DuPont de Nemours Inc., Wilmington, DE, USA, $40.2 \mathrm{wt} \% \mathrm{SiO}_{2}, 8.68 \mathrm{~g} \mathrm{SiO} 2,144.4 \mathrm{mmol}$ $\left.\mathrm{SiO}_{2}\right)$, and Milli-Q water $(1.50 \mathrm{~g})$ were combined in a $150 \mathrm{~mL}$ Teflon vessel. The vessel was tightly capped and the mixture stirred for $3 \mathrm{~h}$ on a hot plate while maintaining a temperature of approximately $60^{\circ} \mathrm{C}$. This procedure was essential to obtaining a clear solution. After cooling to room temperature, a FAU-type zeolite (Tosoh Co., Tokyo, Japan, HSZ-350HUA, $5.03 \mathrm{~g}$; Si/Al = 5.5) was added and the resulting suspension was stirred for $10 \mathrm{~min}$ at room temperature. It should be noted that the synthesis results were found to be sensitive to the FAU-type zeolite manufacturer's lot that was employed, and so the starting gel composition had to be slightly tuned depending on the lot number. For a typical example in this work, the molar composition of the starting gel was $0.265 \mathrm{SiO}_{2}$ (from FAU) $-0.735 \mathrm{SiO}_{2}$ (from colloidal silica) $-0.025 \mathrm{Al}_{2} \mathrm{O}_{3}$ (from FAU) $-0.17 \mathrm{Me}_{2} \mathrm{Pr}_{2} \mathrm{~N}^{+} \mathrm{OH}^{-}-0.15 \mathrm{NaOH}-0.15 \mathrm{KOH}-7.5 \mathrm{H}_{2} \mathrm{O}$. This mixture was transferred to a $125 \mathrm{~mL}$ Teflon-lined stainless-steel autoclave that was subsequently sealed and allowed to stand statically for 4 days in a convection oven at $160{ }^{\circ} \mathrm{C}$. After cooling the autoclave to room temperature, the resulting solid was separated by filtration, washed several times with de-ionized water, and dried overnight. The as-synthesized YNU-5 zeolite was obtained as a white powder $(6.72 \mathrm{~g})$ and was calcined at $550{ }^{\circ} \mathrm{C}$ for $6 \mathrm{~h}$ to remove occluded organics to give the final product $(6.31 \mathrm{~g})$ as a white powder $(\mathrm{Si} / \mathrm{Al}=9.1)$. In order to examine the effect of $\mathrm{H}_{2} \mathrm{O} / \mathrm{SiO}_{2}$ ratio $(w)$ in the starting mixture on the YNU-5 synthesis, the amount of input water was varied as follows. Input amounts were $10.50,8.70,6.91,5.11,3.31,1.50,-0.30$, and $-3.91 \mathrm{~g}$, where $w$ values were 10.0, 9.5, 9.0, $8.5,8.0,7.5,7.0$, and 6.0 , respectively. The negative values mean that the evaporation of excess water by stirring the mixture at approximately $60^{\circ} \mathrm{C}$ on a hot plate $[19,21]$.

The four representative samples used in the present study were prepared by varying the rotation rate $(x$, in rpm) of autoclaves in the oven and crystallization period ( $y$, in days). The "rotation" means rotating the autoclave to mix the contents well; this technique is often used for screening experiments because it is more convenient than the typical stirring system. The rotation rate is one of the important variables for zeolite synthesis $[22,23]$. The YNU-5 samples were synthesized under conditions for which the $(x, y)$ values were $(0,4),(0,7),(20,4)$, and $(20,7)$, and are designated herein as YFI-A, YFI-B, YFI-C, and YFI-D, respectively. The typical procedure described above corresponds to the synthesis of YFI-A.

\subsection{Preparation of MFI-Type Zeolite Nanocrystals}

The typical procedure used to prepare nanocrystals of MFI was as follows. An aqueous solution of $\mathrm{Me}_{2} \mathrm{Pr}_{2} \mathrm{~N}^{+} \mathrm{OH}^{-}$(Sachem Inc., Austin, TX, USA, $2.691 \mathrm{mmol} \cdot \mathrm{g}^{-1}, 1.26 \mathrm{~g}, 3.4 \mathrm{mmol}$ ), $\mathrm{NaOH}\left(11.980 \mathrm{mmol} \cdot \mathrm{g}^{-1}, 0.26 \mathrm{~g}, 3.0 \mathrm{mmol}\right)$ and $\mathrm{KOH}\left(7.914 \mathrm{mmol} \cdot \mathrm{g}^{-1}, 0.38 \mathrm{~g}, 3.0 \mathrm{mmol}\right)$, and colloidal silica (2.65 g; Ludox AS-40, DuPont de Nemours Inc., $40.2 \mathrm{wt} \% \mathrm{SiO}_{2}, 1.07 \mathrm{~g} \mathrm{SiO}_{2}, 17.8 \mathrm{mmol} \mathrm{SiO}_{2}$ ) 
was transferred into a $23 \mathrm{~mL}$ Teflon cup, after which the mixture was stirred at $60{ }^{\circ} \mathrm{C}$. During this process, $0.295 \mathrm{~g}$ of water evaporated from the mixture, after which dealuminated FAU-type zeolite (0.60 g; $\mathrm{SiO}_{2}: 69.7 \mathrm{wt} \%, \mathrm{Al}_{2} \mathrm{O}_{3}: 6.8 \mathrm{wt} \%, \mathrm{H}_{2} \mathrm{O}: 23.5 \mathrm{wt} \%, \mathrm{Si} / \mathrm{Al}=8.7$ ) was added to the clear solution and the resulting suspension stirred for $10 \mathrm{~min}$. The final gel composition was $1.0 \mathrm{SiO}_{2}-0.016 \mathrm{Al}_{2} \mathrm{O}_{3}-$ $0.136 \mathrm{Me}_{2} \mathrm{Pr}_{2} \mathrm{NOH}-0.12 \mathrm{NaOH}-0.12 \mathrm{KOH}-5.6 \mathrm{H}_{2} \mathrm{O}$. This mixture was added to a $23 \mathrm{~mL}$ Teflon-lined stainless steel autoclave that was maintained at $160{ }^{\circ} \mathrm{C}$ in a convection oven without rotation for 7 days. The precipitated solid was separated by centrifugation, washed several times with de-ionized water, and dried overnight at $80^{\circ} \mathrm{C}$. The as-synthesized MFI nanocrystals $(0.46 \mathrm{~g})$ were calcined at $550{ }^{\circ} \mathrm{C}$ for $6 \mathrm{~h}$ to remove occluded organics, giving a product $(0.42 \mathrm{~g}, \mathrm{Si} / \mathrm{Al}=20)$ designated herein as $\mathrm{MFI}_{\text {nano }}(20)$. For comparison purposes, micron-sized ZSM-5 crystals (Si/Al = 19.7), denoted as $\mathrm{MFI}_{\text {micron }}(20)$, were obtained using a synthesis procedure previously reported in the literature [24].

\subsection{Post-Synthesis Modification}

The calcined YNU-5 samples were converted to protonated dealuminated analogues using various acid treatments. Direct dealumination of the calcined YNU-5 (typically $1.0 \mathrm{~g}$ ) was accomplished by refluxing with $0.1-13.4 \mathrm{~mol} \cdot \mathrm{L}^{-1} \mathrm{HNO}_{3}$ solutions $\left(60 \mathrm{~mL}\right.$ (g-sample) $\left.{ }^{-1}\right)$ in a $200 \mathrm{~mL}$ round bottom flask at $130{ }^{\circ} \mathrm{C}$ in an oil bath for $24 \mathrm{~h}$. These conditions also stabilized the framework of the material due to Si migration $[19,21]$. The dealuminated versions of YFI-A, B, C, and D are referred to herein as deAl-YFI-A, B, C, and $\mathrm{D}(n)$, respectively, where $n$ indicates the Si/Al ratio. In this work, as an example, deAl-YFI-A(51), deAl-YFI-B(57), deAl-YFI-C(55), and deAl-YFI-D(63) were prepared by treatment with a $2.0 \mathrm{~mol} \cdot \mathrm{L}^{-1} \mathrm{HNO}_{3}$ solution, while deAl-YFI-C(287) was prepared with a $13.4 \mathrm{~mol} \cdot \mathrm{L}^{-1} \mathrm{HNO}_{3}$ solution under reflux conditions.

In the case of physical mixtures of calcined YNU-5 and small amounts of $\mathrm{MFI}_{\text {nano }}(20)$ or $\mathrm{MFI}_{\text {micron }}(20)$, the calcined materials were first mixed after which the mixture was treated with a $\mathrm{HNO}_{3}$ solution as described above. These mixtures are designated as deAl-[YFI-C $+3 \mathrm{wt} \%$ $\left.\mathrm{MFI}_{\text {nano }}(20)\right]$ and deAl-[YFI-C $\left.+3 \mathrm{wt} \% \mathrm{MFI}_{\text {micron }}(20)\right]$, respectively.

\subsection{Procedure for the DTO Reaction}

Each catalyst was pelletized without a binder, roughly crushed, and then sieved to obtain 500-600 $\mu \mathrm{m}$ particles. These catalyst particles (typically $100 \mathrm{mg}$ ) were placed in a fixed-bed reactor (a down-flow quartz tube microreactor with a $9 \mathrm{~mm}$ internal diameter) situated in an electric furnace. Each sample was first pretreated at $550{ }^{\circ} \mathrm{C}$ for $1 \mathrm{~h}$ under an air flow at $40 \mathrm{~cm}^{3}(\mathrm{NTP}) \mathrm{min}^{-1}$ and then maintained at $400{ }^{\circ} \mathrm{C}$ under a He flow at $40 \mathrm{~cm}^{3}(\mathrm{NTP}) \mathrm{min}^{-1}$, acting as a carrier gas. While maintaining the specimen at $400{ }^{\circ} \mathrm{C}$, DME (at a partial pressure of $5.0 \mathrm{kPa}$ ) was introduced through the top of the reactor. The contact time, $W / F$ (where $W$ value is catalysts weight and $F$ value is flow rate of DME), was $20 \mathrm{~g}$-cat h mol${ }^{-1}$ in these trials but could be varied by changing the flow rate or catalyst amount if necessary. The reactants and products were analyzed by gas chromatography (GC 2014, Shimadzu) using a DB-5 capillary column (Agilent Technologies Inc., Santa Clara, CA, USA; id $0.53 \mathrm{~mm}$, length $30 \mathrm{~m}, 5.00 \mu \mathrm{m}$ thick stationary phrase) and an HP-PLOT/Q capillary column (Agilent Technologies; id $0.53 \mathrm{~mm}$, length $30 \mathrm{~m}, 40.0 \mu \mathrm{m}$ thick stationary phase) together with a flame ionization detector.

\section{Results and Discussion}

\subsection{Synthetic Investigations of YNU-5}

In our previous paper, we reported a drastic effect of the $\mathrm{H}_{2} \mathrm{O} / \mathrm{SiO}_{2}$ molar ratio $(w)$ in the starting gel on the resulting zeolitic phases. Specifically, relatively water-rich conditions promoted crystallization of a zeolitic phase with a higher framework density (FD $\mathrm{Si}_{\mathrm{i}}$ [19]), and it was speculated that a more concentrated gel solution enhanced the degree of interaction between the OSDA molecules and the 
silicate. Further and more detailed investigations of the effects of the $\mathrm{H}_{2} \mathrm{O} / \mathrm{SiO}_{2}$ molar ratio were performed in the present study.

Initially, $w$ was varied from 10 to 6 in 0.5 intervals, and the results are shown in Figure 1. Over this entire range, the major phase was always YFI. However, below a value of 10, an MFI phase was clearly present as a contaminant. The level of this impurity decreased with decreases in the water content, such that pure YNU-5 was obtained at $w=7.5$. As shown in Figure 1, there were no impurity phases other than MFI in the range of 10-7.5. When $w$ was 7.0 or smaller, a MOR phase began to appear although the YFI phase was still almost pure at $w=7.0$. This result is consistent with the hypothesis [21] that more water-rich conditions favor the formation of materials with higher $\mathrm{FD}_{\mathrm{Si}}$ values. In fact, the $\mathrm{FD}_{\mathrm{Si}}$ values of MOR and MFI are 17.0 and 18.4, respectively [19].

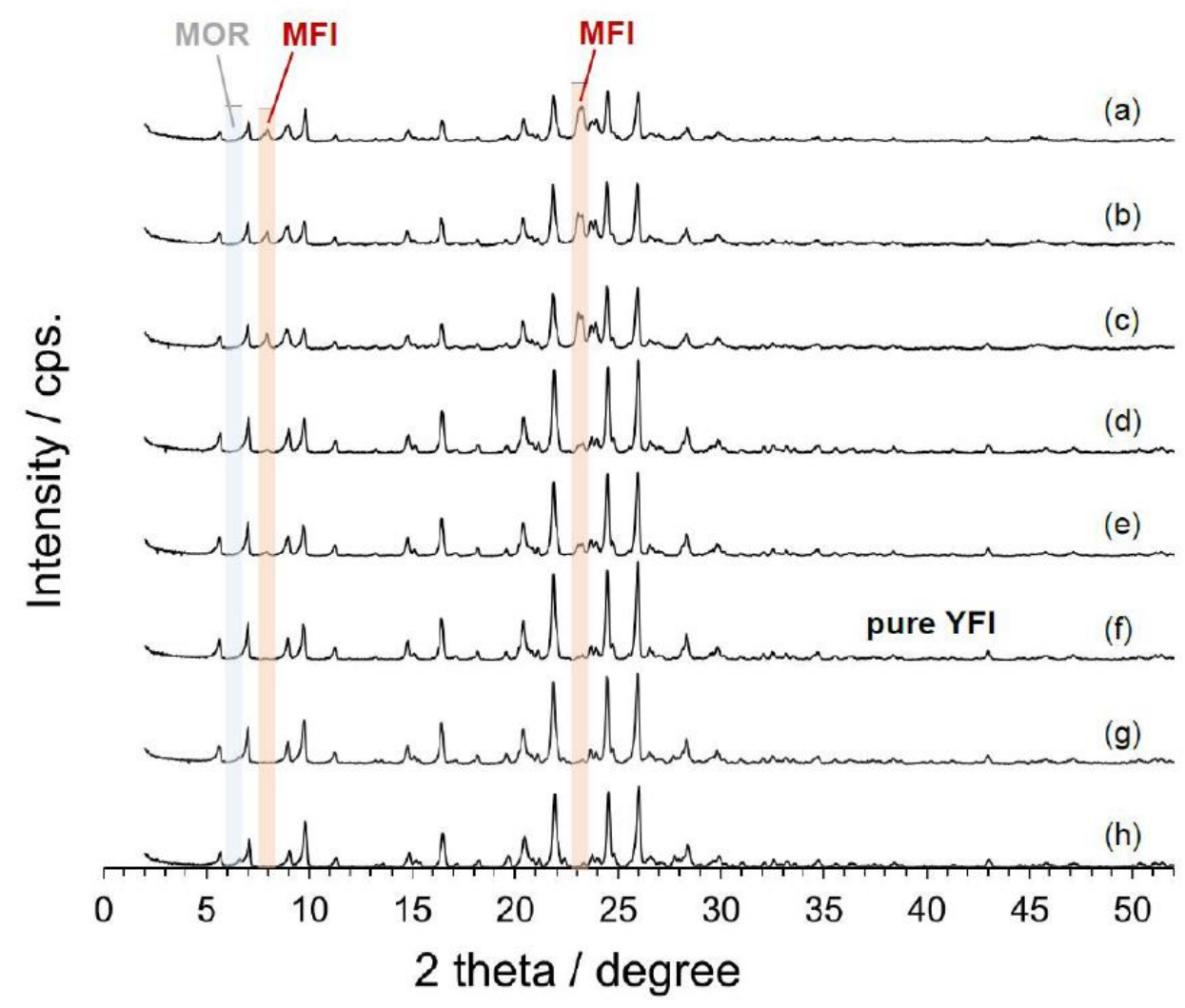

Figure 1. Powder X-ray diffraction patterns showing the effect of water content $\left(w=\mathrm{H}_{2} \mathrm{O} / \mathrm{SiO}_{2}\right.$ molar ratio) in the starting gel on the phase-purity of the product of YNU-5 synthesis. The $w$ values in this series were (a) 10, (b) 9.5, (c) 9, (d) 8.5, (e) 8, (f) 7.5, (g) 7, and (h) 6. The starting gel with molar composition $0.265 \mathrm{SiO}_{2}$ (from $\mathbf{F A U}$ ) $-0.735 \mathrm{SiO}_{2}$ (from colloidal silica) - $0.025 \mathrm{Al}_{2} \mathrm{O}_{3}$ (from FAU) $0.17 \mathrm{Me}_{2} \mathrm{Pr}_{2} \mathrm{~N}^{+} \mathrm{OH}^{-}-0.15 \mathrm{NaOH}-0.15 \mathrm{KOH}-w \mathrm{H}_{2} \mathrm{O}$ was heated under static conditions at $160{ }^{\circ} \mathrm{C}$ for 4 days. The FAU was HSZ-350HUA (Lot \#35UA8301B).

The crystals of the contaminant phases were readily distinguished from the major YFI phase in the FE-SEM images (Figure 2). The MFI phase consisted of sub-micron or nano-sized pillar-like crystals (Figure 2b), whereas the MOR impurity comprised micron-sized crystals (Figure 2c). The fact that a slight change in the water content in the starting gel promoted the formation of impurities suggests that the structure-directing ability of the OSDA, $\mathrm{Me}_{2} \mathrm{Pr}_{2} \mathrm{~N}^{+}$, was not very high. 
(a)

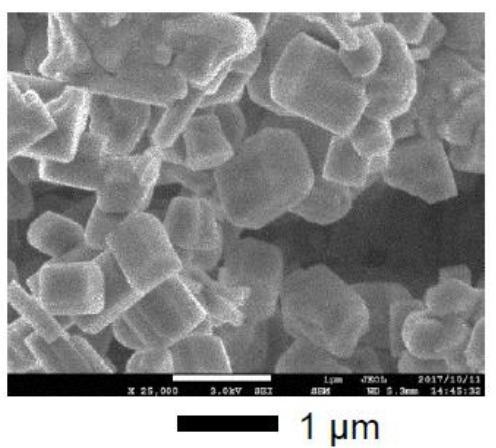

(b)

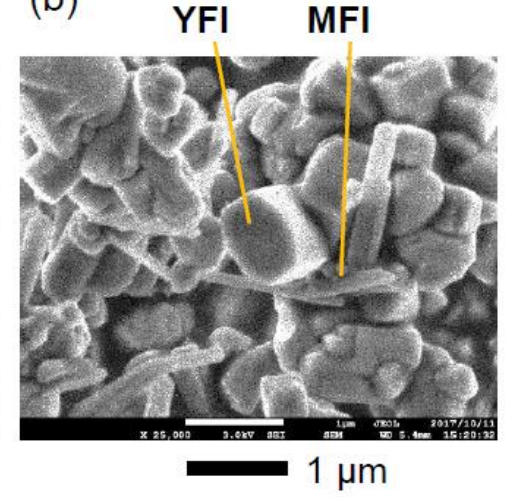

(c)

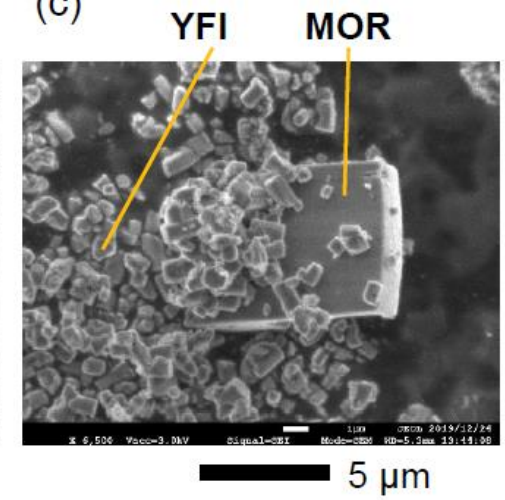

Figure 2. Field emission scanning electron microscopy (FESEM) images of the (a) pure YFI, (b) YFI with trace MFI, and (c) YFI with trace MOR.

The effect of the crystallization period on the YNU-5 product was also investigated, and the time-course of crystallization is presented in Figure 3. The composition of starting mixture and the synthesis conditions are shown in the caption. Figure 3, line a shows the powder XRD pattern of the FAU-type zeolite used as the starting material, while Figure 3, line b demonstrates that the YFI phase began to appear while the major phase was still FAU after 1 day. The FAU phase completely disappeared and a pure YFI phase was observed after 2 days. After 4 days, peaks assignable to an MFI phase appeared and the intensity of these peaks gradually increased upon prolonged heating. In the early stage of the synthesis, it appears that the FAU transformed to YFI; however, it is more likely that the FAU initially dissolved and that some fragments were responsible for the crystallization of YFI, based on other examples of hydrothermal conversion such as from FAU to MSE [25], *BEA to AFI [26,27], and *BEA to *STO [28]. During the investigation on the time-course of crystallization in this work (see Figure 3), the same high level of solids recovery was consistently obtained after 2 days. Even after 1 day, a significant decrease in solid recovery was not observed, indicating that the crystallization rate of the YFI was much greater than the dissolution rate of FAU. The co-crystallized MFI that appeared after 4 days may not have been transformed from YFI but rather was generated as a result of independent nucleation from the mother gel. The FE-SEM image in Figure $2 b$ is consistent with this hypothesis because it shows that crystals of YFI and MFI existed independently. Crystallization for a span of 2-3 days appears to have given the highest degree of phase purity. However, in the present work, we tuned the synthesis conditions so as to require crystallization times in the range of 4-7 days, and found interesting results with regard to the catalytic performance of the materials.

Rotation of the synthesis vessel during the synthesis (see Section 2.2) is sometimes a key factor affecting the final products. As an example, topological changes from MFI to TON-type zeolites when using $n$-butylamine and 1,6-diaminohexane as the OSDAs were observed upon going from static to rotating conditions in a prior work [22]. Thus, to further examine the relationship between synthesis conditions and the formation of second phases, the effects of rotation and the crystallization period were also investigated in the present research. In these trials, the rotation rate ( $x$, in rpm) and crystallization period ( $y$, in days) were varied such that the $(x, y)$ pairs were $(0,4),(0,7),(20,4)$, and $(20,7)$, while keeping the other parameters constant. The resulting samples are denoted herein as YFI-A, YFI-B, YFI-C, and YFI-D, respectively, and the results are summarized in Figure 4. These data demonstrate that the appearance of trace amounts of MFI as an impurity was more effectively suppressed when $x$ was larger and $y$ was smaller. The best results were obtained at $(x, y)=(20,4)$, such that the corresponding YFI-C sample comprised a pure YFI phase (Figure 4, line c). In addition, regardless of the rotation rate, longer crystallization times increased the probability of forming the MFI impurity, although the amounts of this phase remained almost negligible. 

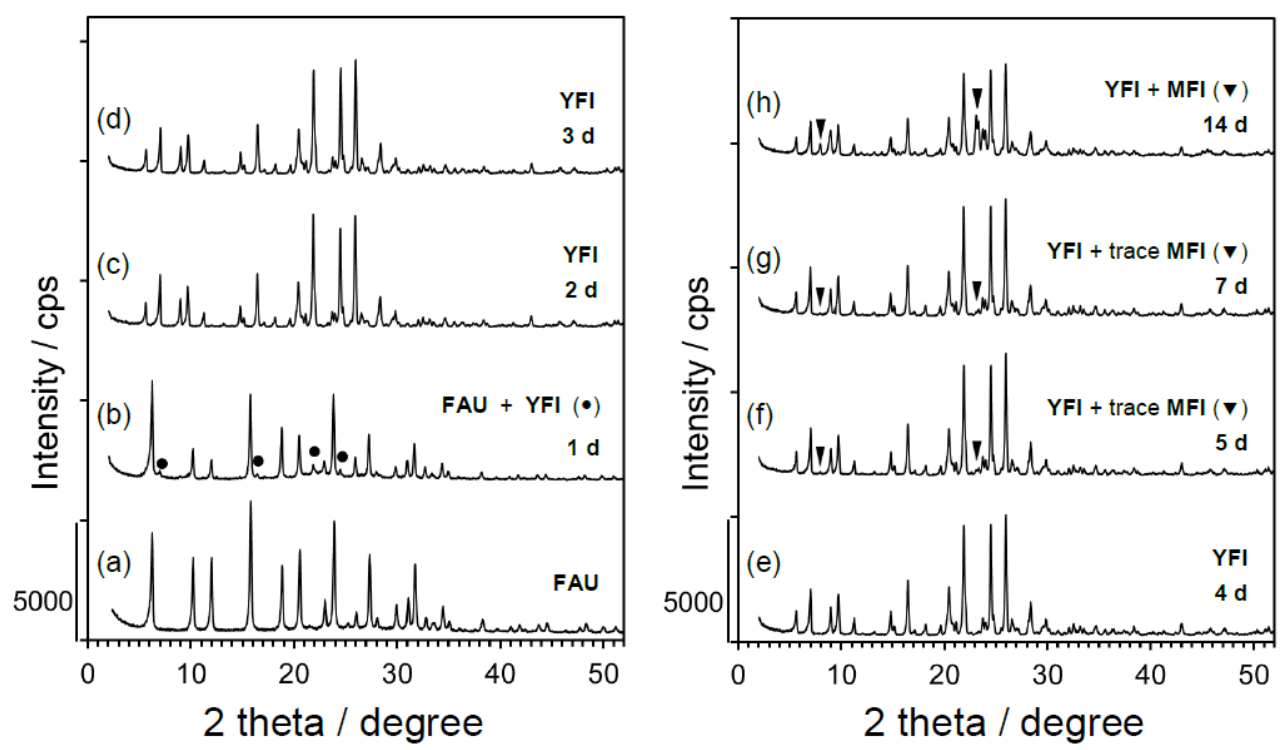

Figure 3. Phase changes over time as reflected in the powder X-ray diffraction patterns of (a) the starting material (FAU) and (b-h) as-synthesized samples crystallized under static conditions at $160{ }^{\circ} \mathrm{C}$. The starting molar composition was $0.265 \mathrm{SiO}_{2}$ (from $\mathbf{F A U}$ ) $-0.735 \mathrm{SiO}_{2}$ (from colloidal silica) $-0.025 \mathrm{Al}_{2} \mathrm{O}_{3}$ (from FAU) $-0.17 \mathrm{Me}_{2} \mathrm{Pr}_{2} \mathrm{~N}^{+} \mathrm{OH}^{-}-0.15 \mathrm{NaOH}-0.15 \mathrm{KOH}-7.0 \mathrm{H}_{2} \mathrm{O}$. The FAU was HSZ-350HUA (Lot \#35UA3Y02).

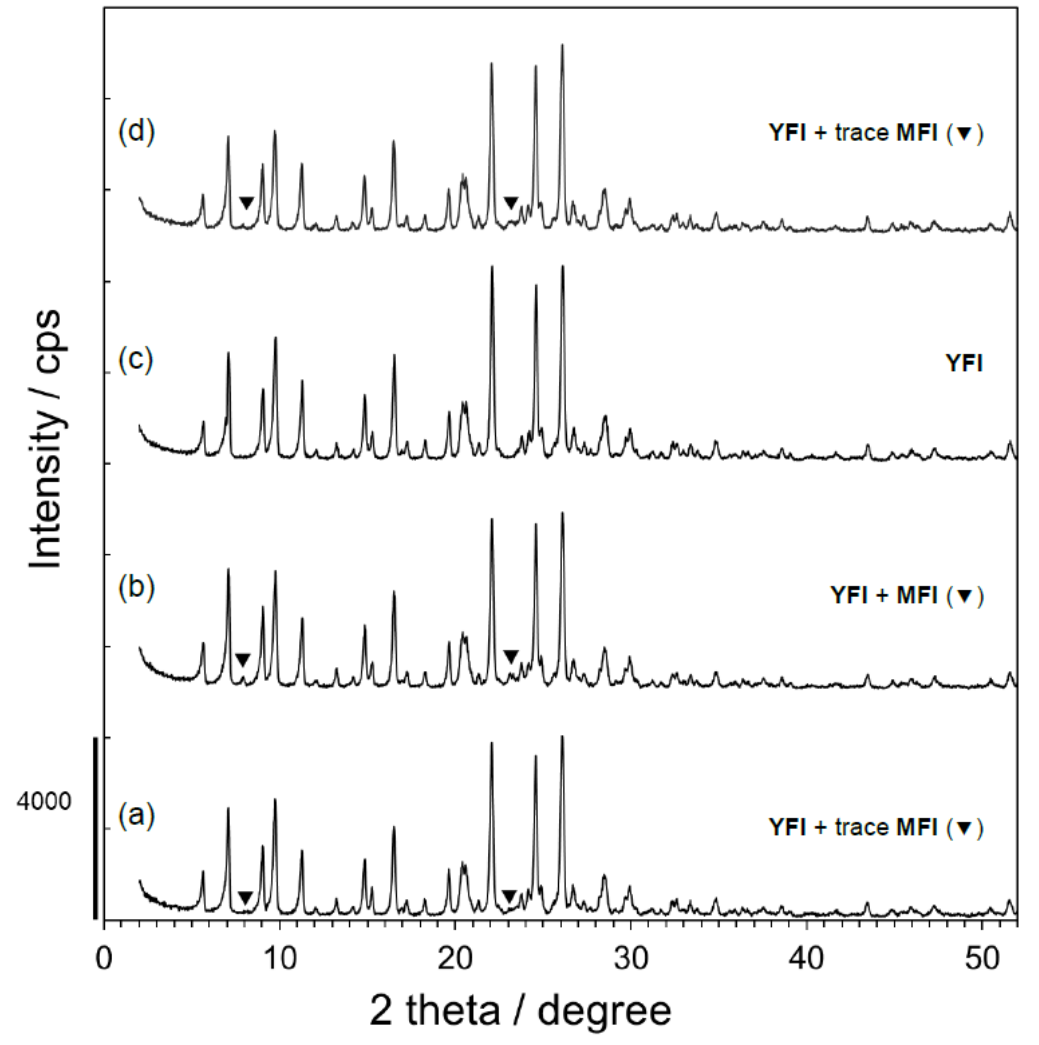

Figure 4. Powder X-ray diffraction patterns for calcined forms of (a) YFI-A, (b) YFI-B, (c) YFI-C, and (d) YFI-D crystallized while varying the rotation rate $(x, \mathrm{rpm})$ and crystallization period ( $y$, days), with $(x, y)$ values of (a) $(0,4),(b)(0,7),(c)(20,4)$, and (d) $(20,7)$. The nomenclature for these samples is explained in Section 2.2. The starting molar composition was $0.265 \mathrm{SiO}_{2}$ (from FAU) $-0.735 \mathrm{SiO}_{2}$ (from colloidal silica) - $0.025 \mathrm{Al}_{2} \mathrm{O}_{3}$ (from FAU) $-0.17 \mathrm{Me}_{2} \mathrm{Pr}_{2} \mathrm{~N}^{+} \mathrm{OH}^{-}-0.15 \mathrm{NaOH}-0.15 \mathrm{KOH}-7.0 \mathrm{H}_{2} \mathrm{O}$. The FAU was HSZ-350HUA (Lot \#35UA3Y02). 


\subsection{Effects of a Trace of MFI on the Physicochemical Properties of YFI Samples}

The effects of trace amounts of MFI, the most frequent contaminant, on some physicochemical properties of bulk YNU-5 samples were investigated, employing the YFI-A-D that are discussed in the previous section and shown in Figure 4. Since the original material was composed of a very pure YFI phase, it was possible to establish the effects of contaminants by comparing this specimen with three other samples: YFI-A, B, and D. The trace amount of MFI did not affect the bulk chemical composition of the material as revealed by ICP analysis (Table S1).

Figure $\mathrm{S} 1$ presents the ${ }^{27} \mathrm{Al}$ MAS NMR spectra of the YNU-5 samples (YFI-A-YFI-D) acquired immediately after removing the OSDA by calcination at $550{ }^{\circ} \mathrm{C}$ for $6 \mathrm{~h}$. All these spectra are similar and the major peaks in the range of 50-60 ppm are assignable to tetrahedral aluminum, indicating that the majority of the aluminum atoms were incorporated into the framework. The minor peak at approximately $0 \mathrm{ppm}$ is ascribed to octahedral $\mathrm{Al}$, which tends to appear in calcined samples and was not observed in the as-synthesized YNU-5 samples. Figure S2 provides the ${ }^{29}$ Si MAS NMR spectra of the calcined YNU-5 samples. The spectra for samples A, B, and D (Figure S2, lines a,b,d, respectively) are seen to be similar to that produced by the pure calcined YNU-5 sample YFI-C (Figure S2, line c). It is interesting to note that the framework $\mathrm{Si} / \mathrm{Al}$ ratios estimated from the ${ }^{29} \mathrm{Si}$ MAS NMR spectra are slightly higher than the bulk Si/Al ratios determined by ICP analysis (Table S1), which is consistent with the ${ }^{27} \mathrm{Al}$ MAS NMR results. At this stage, no obvious differences were observed among samples A-D.

To assess the application of these materials as solid acid catalysts, samples A-D (in calcined form) were dealuminated with $2 \mathrm{~mol} \cdot \mathrm{L}^{-1} \mathrm{HNO}_{3}$ in a $130{ }^{\circ} \mathrm{C}$ oil bath for $24 \mathrm{~h}$ [20]. It was confirmed by XRD that the samples maintained a high degree of crystallinity after dealumination (see Figure S3). Figure 5 shows the ammonia temperature-programmed desorption $\left(\mathrm{NH}_{3}-\mathrm{TPD}\right)$ profiles for these same samples along with the acid amounts (that is, the number of acid sites) estimated from the so-called $h$-peak for each material $[29,30]$. The discrepancy between the $\mathrm{Al}$ content $\left(0.224 \mathrm{mmol}-\mathrm{Al} \mathrm{g}^{-1}\right)$ determined by ICP analysis (see Figure 5 caption) and the number of acid sites $\left(0.249 \mathrm{mmol} \cdot \mathrm{g}^{-1}\right)$ estimated by $\mathrm{NH}_{3}$-TPD for the pure YFI (YFI-C) was not unexpected and was in good agreement with the results of our previous studies concerning other zeolites [31]. Underestimation of acid amounts by $\mathrm{NH}_{3}-\mathrm{TPD}$ compared to the $\mathrm{Al}$ content determined by ICP analysis is very common and there are some possible reasons for this. These include the existence of non-acidic extra-framework $\mathrm{Al}$ atoms [32], inaccessible tetrahedral $\mathrm{Al}$ sites in the framework, and residual $\mathrm{K}^{+}$at [Si-O-Al]- sites in the framework. These effects are typical in the case of the parent samples before dealumination; however, the number of acid sites in each dealuminated YFI sample was closer to the bulk $\mathrm{Al}$ content, together with a K/Al molar ratio of less than 0.01 . At the dealuminated stage, the $\mathrm{NH}_{3}$-TPD profiles are very similar between the YFI-A-D specimens, regardless of the effects discussed immediately above.

Overall, the similarities in the $\mathrm{Si} / \mathrm{Al}$ ratios, framework characteristics, and even acid properties indicate that the presence of trace amounts of impurities had no obvious effects on the physicochemical properties of the YNU-5 in the case that the extent of contamination was as low as in these specimens. 


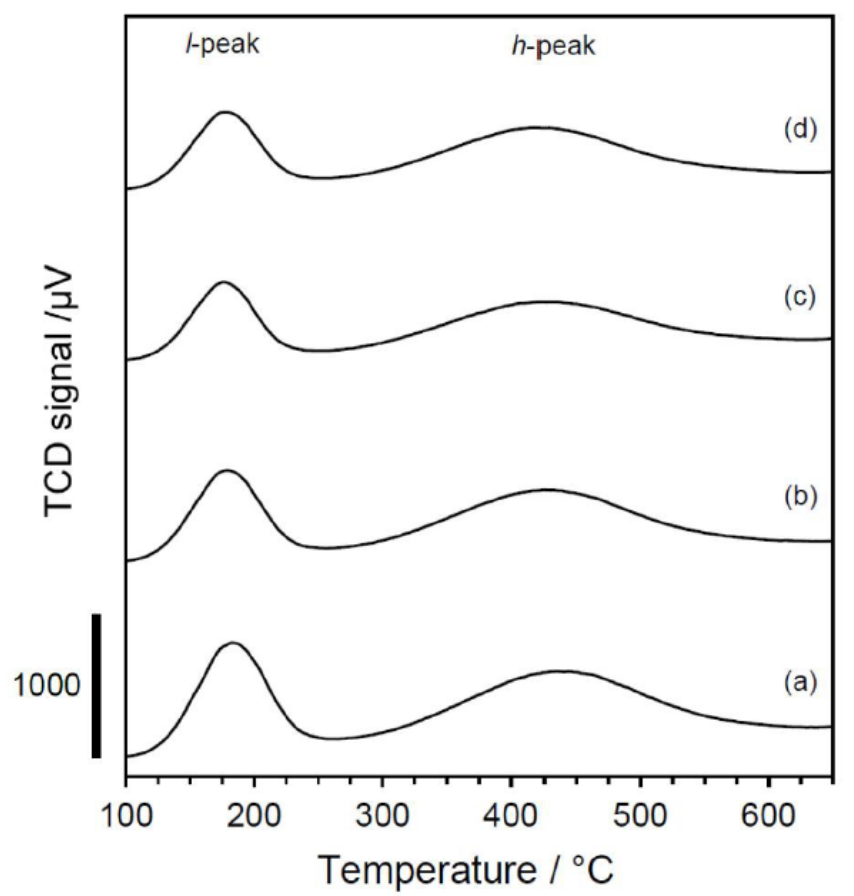

Figure 5. The $\mathrm{NH}_{3}$-temperature programmed desorption profiles for the (a) deAl-YFI-A(51), (b) deAl-YFI-B(57), (c) deAl-YFI-C(55), and (d) deAl-YFI-D(63). The acid concentrations determined from the $h$ peaks are (a) 0.258 , (b) 0.290 , (c) 0.224 , and $0.249 \mathrm{mmol} \cdot \mathrm{g}^{-1}$, respectively. The Al levels determined by ICP analysis are (a) 0.325 , (b) 0.319 , (c) 0.267 , and $0.301 \mathrm{mmol} \cdot \mathrm{g}^{-1}$, respectively. As explained in Section 2.4, the dealuminated versions of YFI-A, B, C, and D are referred to herein as deAl-YFI-A, B, C, and $\mathrm{D}(n)$, respectively, where $n$ indicates the $\mathrm{Si} / \mathrm{Al}$ ratio.

\subsection{DTO Reaction over the YFI Catalyst}

\subsubsection{Effect of MFI as a Trace Contaminant}

The conversion of DME is an attractive alternative approach to the sustainable production of olefins and could replace the classical routes based on the thermal cracking of ethane [33]. DME is commonly obtained from the dehydration of methanol acquired from non-fossil resources such as natural gas, coal, biomass, or waste gasification/reforming [34]. Due to its low cost and high hydrocarbon selectivity, the DTO reaction has become increasingly attractive in recent years $[35,36]$. The present work focused on performing this reaction catalyzed by zeolite-based solid acid materials with the expectation of obtaining high selectivity for propylene and butenes [31]. In the previous section, we reported almost no effect of trace contamination on the physicochemical properties of these catalysts. In contrast, small amounts of impurities had profound effects on the DTO reaction when using deAl-YFI-C(55) (that is, a pure YFI phase) and deAl-YFI-B(57) (YFI containing approximately $3 \mathrm{wt} \%$ of an MFI phase).

Figure $6 \mathrm{a}, \mathrm{b}$ shows the conversions as well as product distributions over deAl-YFI-C(55) and deAl-YFI-B(57), respectively. The conversions were high after a short TOS (5 $\mathrm{min})$ over both catalysts. However, in the case of the deAl-YFI-C(55), a rapid decrease in conversion was observed as the TOS increased. In fact, conversion decreased to $<40 \%$ at a TOS of $65 \mathrm{~min}$. This result demonstrates that the pure YNU-5 catalyst deactivated rapidly during the DTO reaction. After the removal of acid sites on the external surfaces and pore mouths (preferentially the 12-ring pores) by the acid treatment, the remaining acid sites on the pore mouths of isolated 8-rings may have directly promoted coke formation [21]. The detailed location of the remaining acid site after deep dealumination will be investigated in future work. The most surprising finding was that this phenomenon changed when deAl-YFI-B(57) was used as the catalyst, such that the deactivation of the YNU-5 was greatly suppressed and the conversion remained high even at a TOS of $305 \mathrm{~min}$. The thermogravimetric 
analysis of the spent catalysts indicated there was no significant difference in the amount of coke deposition between deAl-YFI-C(55) and deAl-YFI-B(57) in Figure 6. This suggests that the long-lived active sites in deAl-YFI-B(57) are not influenced by currently observed coke formation even though some different active sites are deactivated.

(a)

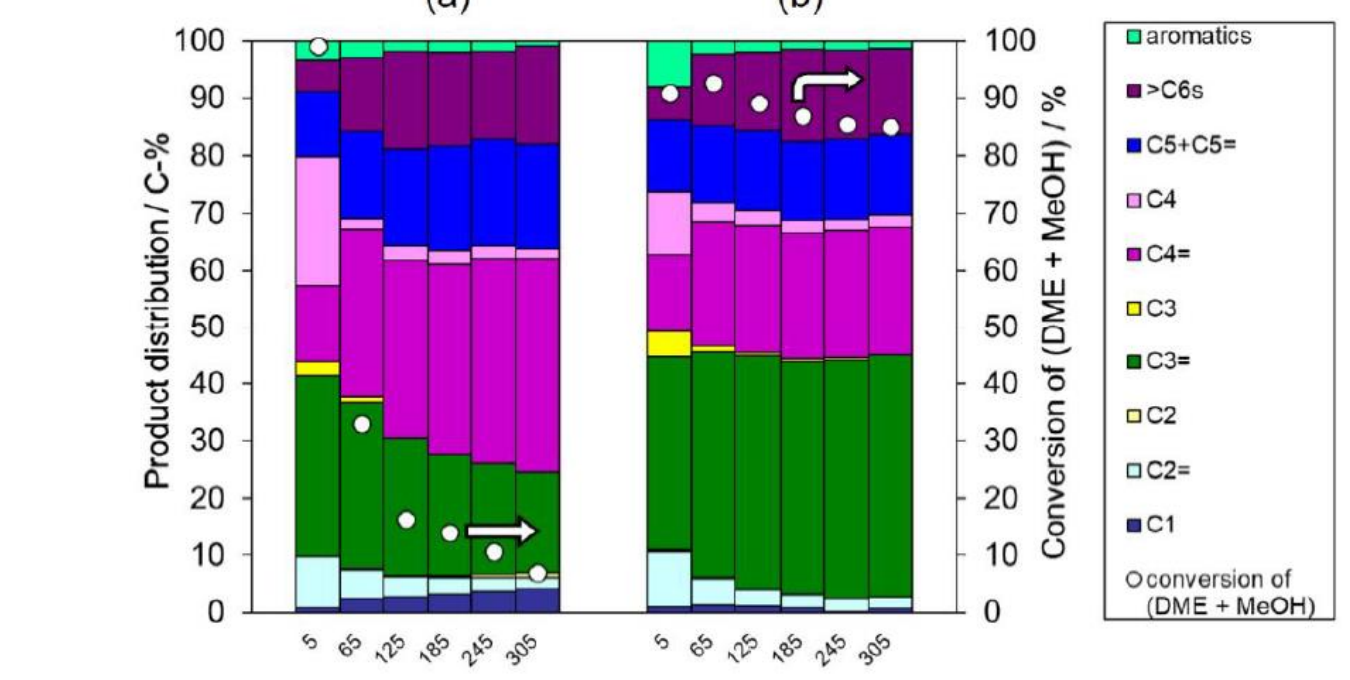

(b)

Figure 6. Results from the dimethyl ether (DME)-to-olefin (DTO) reaction over the (a) deAl-YFI-C(55) and (b) deAl-YFI-B(57). Pretreatment conditions: $550{ }^{\circ} \mathrm{C}, 1 \mathrm{~h}$ under an air flow of $40 \mathrm{~cm}^{3}(\mathrm{NTP}) \mathrm{min}^{-1}$. Reaction conditions: catalyst weight, $100 \mathrm{mg} ; \mathrm{W} / F=20 \mathrm{~g}$-cat h mol${ }^{-1}$; pellet size, $500-600 \mu \mathrm{m}$; He flow rate, $40 \mathrm{~cm}^{3}(\mathrm{NTP}) \cdot \mathrm{min}^{-1}$; temperature, $400{ }^{\circ} \mathrm{C}$. As explained in Section 2.4, the dealuminated versions of YFI-A, B, C, and D are referred to herein as deAl-YFI-A, B, C, and D $(n)$, respectively, where $n$ indicates the $\mathrm{Si} / \mathrm{Al}$ ratio. Coke amounts in the spent catalysts estimated by thermogravimetric analyses were (a) 91 and (b) $105 \mathrm{mg}$ (g-cat) ${ }^{-1}$.

To determine if the small amounts of impurities were responsible for the significant changes in performance, we intentionally mixed YFI-C (that is, pure YNU-5) with trace amounts of $\mathrm{MFI}_{\text {nano }}(20)$ or $\mathrm{MFI}_{\text {micron }}(20)$, dealuminated using a standard technique to compare with deAl-YFI-B(57), and used the resulting deAl-[YFI-C + $\left.3 \mathrm{wt} \% \mathrm{MFI}_{\text {nano }}(20)\right]$ and deAl-[YFI-C + $\left.3 \mathrm{wt} \% \mathrm{MFI}_{\text {micron }}(20)\right]$ (as defined in Section 2.4) as catalysts for the DTO reaction. Note that the abbreviations $\mathrm{MFI}_{\text {nano }}(20)$ and $\mathrm{MFI}_{\text {micron }}(20)$ used here are as defined in Section 2.3. The particle sizes and morphologies of these samples were confirmed by FE-SEM, as shown in Figure 7. The $\mathrm{MFI}_{\text {nano }}(20)$ or $\mathrm{MFI}_{\text {micron }}$ (20) was added at $3 \mathrm{wt} \%$ based on physically mixing pure calcined YNU-5 (YFI-C) with $\mathrm{MFI}_{\text {micron }}$ (20) so that the YFI-C:MFI micron $(20)$ weight ratio was 97:3, 95:5, or 90:10. Comparing the YFI-B to these mixtures, the amount of the MFI phase in the YFI-B was estimated to be $3 \mathrm{wt} \%$.

To allow a comparison with the deAl-YFI-B(57) (Figure 6b), the catalytic performances of the physical mixtures are summarized in Figure $8 \mathrm{a}, \mathrm{b}$. During the initial stage of the reaction (TOS $<5 \mathrm{~min}$ ), the YFI phase evidently acted as the main catalyst. However, the deAl-YFI-C(55) was rapidly deactivated due to coke formation (Figure 6a). After this initial stage (TOS $>5 \mathrm{~min}$ ), it appears that the MFI phase primarily catalyzed the reaction. Compared to the data for deAl-YFI-C(55) in Figure 8a, it is evident that deactivation was effectively suppressed when using the deAl-[YFI-C $\left.+3 \mathrm{wt} \% \mathrm{MFI}_{\text {nano }}(20)\right]$ $(\mathrm{Si} / \mathrm{Al}=57$, Figure $8 \mathrm{a})$ or deAl-[YFI-C + $\left.3 \mathrm{wt} \% \mathrm{MFI}_{\text {micron }}(20)\right](\mathrm{Si} / \mathrm{Al}=62$, Figure 8b). Only minimal deactivation was observed in both cases at TOS values between 5 and 185 min. Unexpectedly, with further increases in TOS, a significant decrease in conversion occurred when using the deAl-[YFI-C + $\left.3 \mathrm{wt} \% \mathrm{MFI}_{\text {micron }}(20)\right]$. In contrast, the conversion was maintained at $80 \%$ at a TOS of 305 in the case of the nanosized MFI deAl-[YFI-C + $\left.3 \mathrm{wt} \% \mathrm{MFI}_{\text {nano }}(20)\right]$. In this case, the selectivity for propene (a C3=) greatly increased as well. It should be noted that the samples made via the intentional physical mixing of $\mathrm{MFI}_{\text {nano }}$ showed very similar catalytic performance (Figure 8a) to that in Figure 6b, which suggests 
that trace levels of $\mathrm{MFI}_{\text {nano }}$ were responsible for the long life of the deAl-YFI-B(57). The fact that typical micron-sized MFI particles exhibited a lesser effect (Figure 8b) indicates the advantage of the nano-sized MFI contaminant. A control experiment was carried out as follows. $\mathrm{MFI}_{\text {nano }}(20)$ was physically mixed with inert material $\mathrm{Si}_{3} \mathrm{~N}_{4}$ at the weight ratio of 3:97 after which the mixture was treated with a $\mathrm{HNO}_{3}$ solution as described in Section 2.4. The solid mixture was designated as deAl-[ $\left[\mathrm{Si}_{3} \mathrm{~N}_{4}+3 \mathrm{wt} \%\right.$ $\left.\mathrm{MFI}_{\text {nano }}(20)\right]$ and was used as catalyst for DTO reaction (Figure $8 \mathrm{c}$ ). As a result, the deAl-[Si $3 \mathrm{~N}_{4}+$ $3 \mathrm{wt} \% \mathrm{MFI}_{\text {nano }}(20)$ ] showed stable activity as well as the similar product distribution pattern to that in Figure 8a, which further confirms this extraordinary advantage of $\mathrm{MFI}_{\text {nano }}(20)$. The most interesting aspect of these data is that the formation of a trace amount of co-crystallized MFI along with the crystallization of YNU-5 produced similar results to the material with added $\mathrm{MFI}_{\text {nano. }}$.

(a)

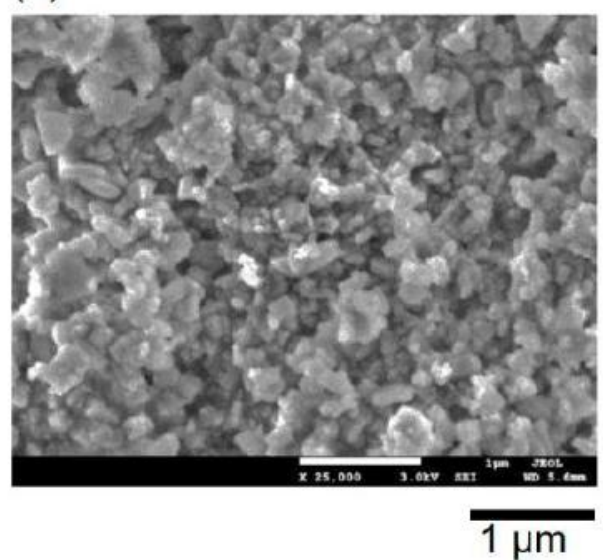

(b)

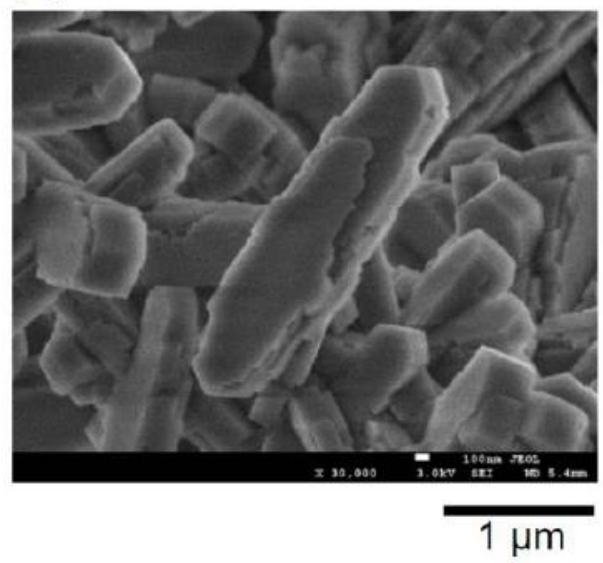

Figure 7. Field emission scanning electron microscopy images of the (a) $\operatorname{MFI}_{\text {nano }}(20)$ and (b) $\mathrm{MFI}_{\text {micron }}(20)$. The nomenclature for these samples is explained in Section 2.3.

(a)

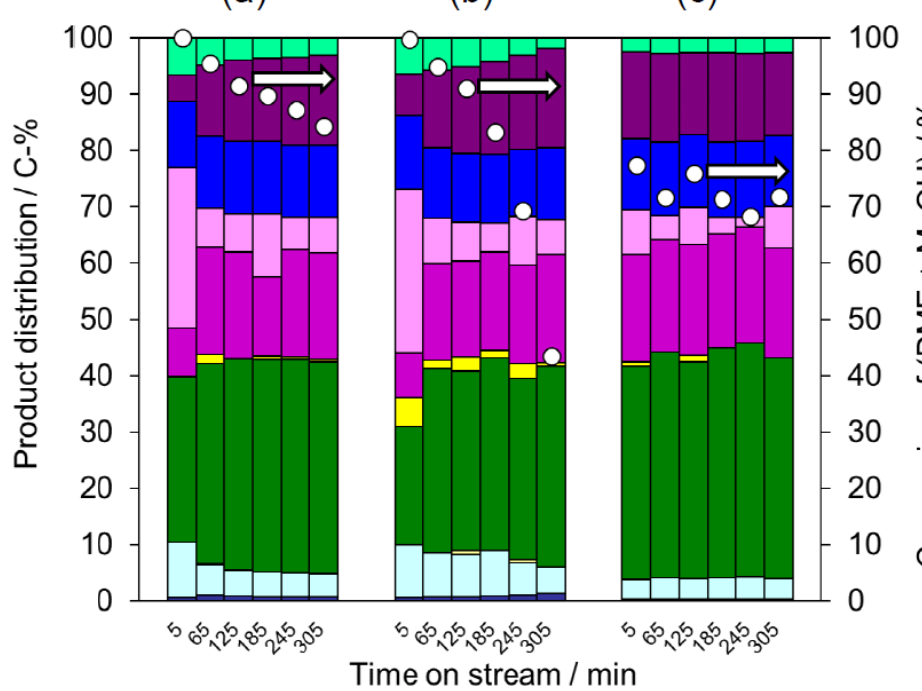

(c)

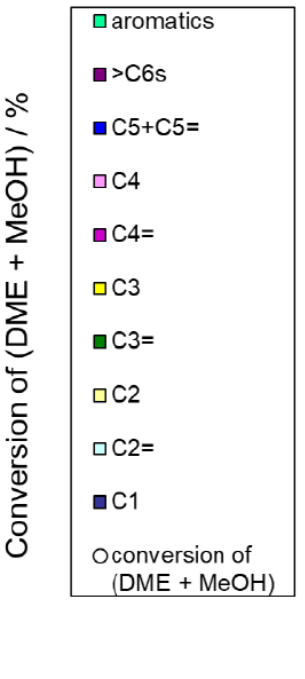

Figure 8. Results from the DTO reaction over the (a) deAl-[YFI-C $\left.+3 w t \% \mathrm{MFI}_{\text {nano }}(20)\right](\mathrm{Si} / \mathrm{Al}=62)$, (b) deAl-[YFI-C + $\left.3 \mathrm{wt} \% \mathrm{MFI}_{\text {micron }}(20)\right](\mathrm{Si} / \mathrm{Al}=62)$, and (c) deAl-[ $\left.\mathrm{Si}_{3} \mathrm{~N}_{4}+3 \mathrm{wt} \% \mathrm{MFI}_{\text {nano }}(20)\right]$. The nomenclature for these samples is explained in Section 2.4 for (a) and (b), and Section 3.3.1 for (c). Pretreatment conditions: $550{ }^{\circ} \mathrm{C}, 1 \mathrm{~h}$ under air at a flow rate of $40 \mathrm{~cm}^{3}(\mathrm{NTP}) \mathrm{min}^{-1}$. Reaction conditions: catalyst weight, $100 \mathrm{mg} ; W / F=20 \mathrm{~g}$-cat $\mathrm{h} \mathrm{mol}^{-1}$; pellet size, 500-600 $\mu \mathrm{m}$; He flow rate, $40 \mathrm{~cm}^{3}(\mathrm{NTP}) \cdot \mathrm{min}^{-1}$; temperature, $400{ }^{\circ} \mathrm{C}$. Coke amounts in the spent catalysts estimated by thermogravimetric analyses were (a) 114 and (b) $94 \mathrm{mg}$ (g-cat) ${ }^{-1}$. 


\subsubsection{Catalytic Characteristics of Pure YNU-5}

Because we succeeded in obtaining very pure YNU-5, we investigated the intrinsic catalytic features of this 12-12-8-ring zeolite by comparing its catalytic performance with those of 8-ring and 12-ring zeolites. SSZ-13 (having a CHA topology with an 8-8-8-ring pore system) and beta (having a ${ }^{*}$ BEA topology with a 12-12-12-ring pore system) were used as model catalysts for the DTO reaction. Figure 9 summarizes the product distributions obtained from this reaction when catalyzed by the SSZ-13 (Si/Al = 136, Figure 9a), deAl-YFI-C(287) (Figure 9b,c), and beta (Figure 9d) materials. It is obvious that the SSZ-13 gave very high C2= selectivity as high as $35 \%$ at a conversion of $88 \%$ (Figure $9 \mathrm{a}$ ). In contrast, the $\mathrm{C} 3=$ and $\mathrm{C} 4=$ selectivities obtained from the beta were remarkably high, with a combined $[\mathrm{C} 3=+\mathrm{C} 4=]$ selectivity of approximately $65 \%$ in conjunction with a conversion of $85 \%$ (Figure 9d). Thus, the product distributions tended to reflect the pore system in the catalyst. To obtain comparable conversion levels, the W/F value was increased by a factor of 4 when using the YNU-5, with the results presented in Figure 9c. The DTO reaction catalyzed by the highly dealuminated YNU-5 (deAl-YFI-C(287)) gave a product distribution pattern that was very similar to that obtained from the reaction over the beta specimen $(\mathrm{Si} / \mathrm{Al}=250)($ Figure $9 \mathrm{c}, \mathrm{d})$. At a conversion of $80 \%$, the selectivity for $[C 3=+C 4=]$, which are the products in growing demand at present [37-39], was close to $60 \%$ (Figure 9c), suggesting that this material could have practical applications. Thus, the behavior of the highly dealuminated YNU-5 was closer to that of a 12-ring system rather than an 8-ring zeolite catalyst. This result could assist in determining the locations of acid sites in the YNU-5 catalyst, and more detailed investigations of these effects are currently underway in our laboratory.

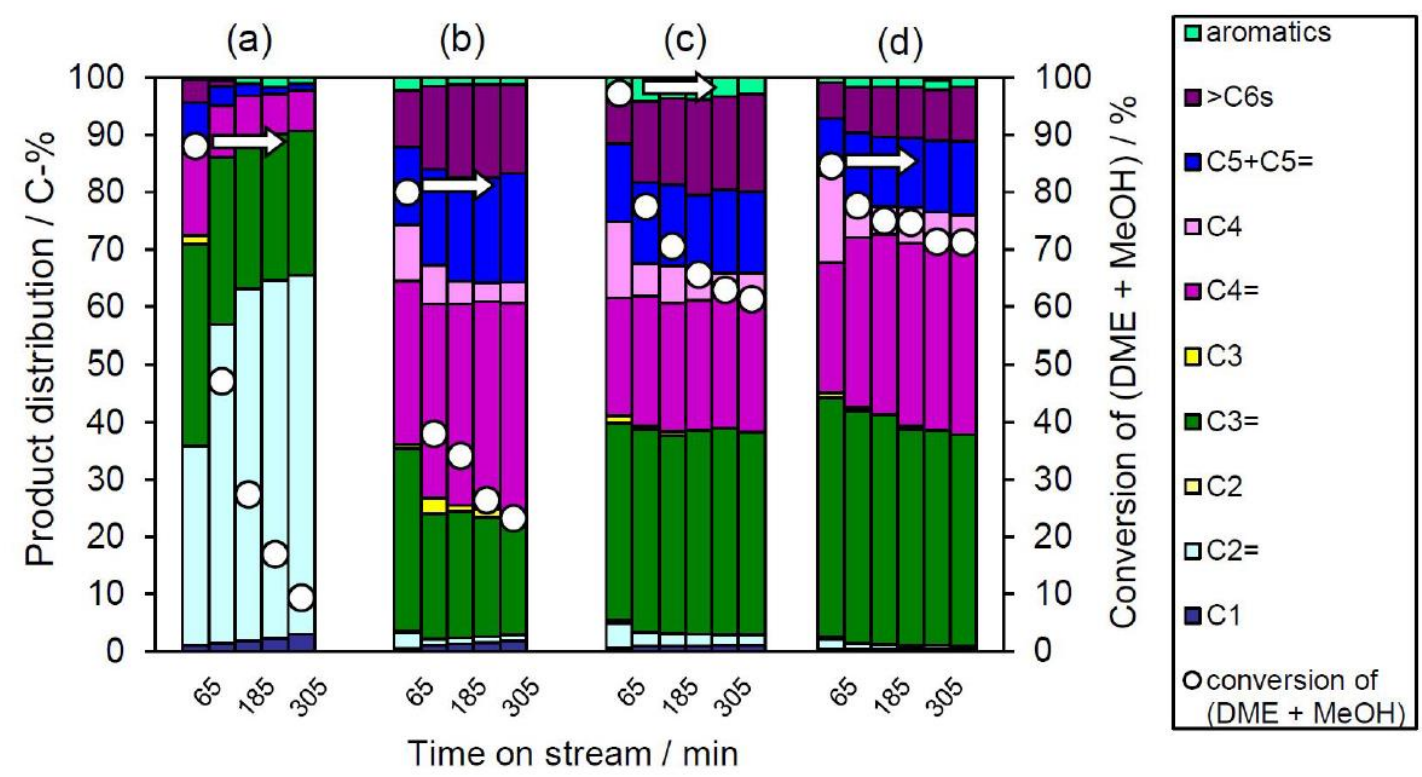

Figure 9. Results from the DTO reaction over the (a) SSZ-13 ( $\mathrm{Si} / \mathrm{Al}=136)$, (b,c) deAl-YFI-C(287), and (d) beta $(\mathrm{Si} / \mathrm{Al}=250)$. Pretreatment conditions: $550{ }^{\circ} \mathrm{C} ; 1 \mathrm{~h}$ under an air flow of $40 \mathrm{~cm}^{3}(\mathrm{NTP}) \cdot \mathrm{min}^{-1}$. Reaction conditions: catalyst weight, $100 \mathrm{mg} ; \mathrm{W} / F=20 \mathrm{~g}$-cat $\mathrm{h} \mathrm{mol}^{-1}$ with the exception of $(\mathrm{c})$ where $W / F=79$ g-cat h mol${ }^{-1}$; pellet size, 500-600 $\mu \mathrm{m}$; He flow rate, $40 \mathrm{~cm}^{3}(\mathrm{NTP}) \mathrm{min}^{-1}$; reaction temperature, $400{ }^{\circ} \mathrm{C}$. The nomenclature for deAl-YFI-C(287) is explained in Section 2.4. Coke amounts in the spent catalysts estimated by thermogravimetric analyses were (a) 91, (b) 29, (c) 25, and (d) 19 mg (g-cat) ${ }^{-1}$.

\section{Conclusions}

Following the successful synthesis and structural determination of YNU-5 having a YFI framework [19], it became important to assess several aspects of this material with regard to potential catalytic applications. This included defining the factors that affect crystallization [21], preparing a high-silica YNU-5 catalyst with a stable framework [21], and establishing the relationship between 
very small amounts of impurity phases and catalytic performance. The present study examined the first and third issues. During the synthesis investigation, it was found that a very slight amount of an impurity phase tended to be formed along with the desired product YNU-5. This minor phase was very often MFI. The phase selection was sensitive to the levels of water in the synthesis mixture, such that a pure phase could be produced but it was also possible to intentionally form specific trace impurities. Dealuminated pure YNU-5 showed rapid deactivation at TOS values greater than $5 \mathrm{~min}$, while the presence of low levels of ZSM- 5 as an impurity reduced the extent of deactivation. At a TOS of $305 \mathrm{~min}$, conversions up to $80 \%$ were observed. During the initial reaction stage, the YNU-5 acted as the primary catalyst and showed selectivity for propene as high as $30 \%$. When TOS was between 5 and $305 \mathrm{~min}$, ZSM- 5 was the main catalyst and provided selectivity for propene up to $40 \%$. This enhanced selectivity was observed only in the case that the ZSM-5 comprised nanoparticles. It is worth noting that the ZSM-5 impurity in the synthesis system of YNU-5 was unlike typical ZSM- 5 specimens in that it appeared in the form of nano-sized particles. The presence of this nanoparticle contaminant phase evidently improved the performance of the catalytic system during the DTO reaction. Based on the product distribution obtained using highly dealuminated, very pure YNU-5 as a solid acid catalyst, this material behaves more like a 12-ring zeolite. The highly dealuminated YNU-5 also shows increased selectivity for high value $\mathrm{C} 3$ and $\mathrm{C} 4$ olefins, which suggests potential practical applications.

Supplementary Materials: The following are available online at http://www.mdpi.com/1996-1944/13/9/2030/s1, Table S1: Elemental analysis and related data of YFI samples. Figure S1: ${ }^{27} \mathrm{Al}$ magic angle spinning nuclear magnetic resonance $\left({ }^{27} \mathrm{Al}\right.$ MAS NMR) spectra obtained from the (a) YFI-A, (b) YFI-B, (c) YFI-C, and (d) YFI-D. Figure S2: ${ }^{29}$ Si MAS NMR spectra obtained from the (a) YFI-A, (b) YFI-B, (c) YFI-C, and (d) YFI-D. Figure S3: Powder X-ray diffraction patterns obtained from the (a) deAl-YFI-A(51), (b) deAl-YFI-B(57), (c) deAl-YFI-C(55), and (d) deAl-YFI-D(63).

Author Contributions: Conceptualization, Y.K. and S.I.; methodology, N.N. and Y.K.; formal analysis, Y.Y., Q.L.; investigation, Y.Y. and Q.L.; data curation, Y.Y. and Q.L.; writing-original draft preparation, Q.L. and Y.K.; writing-review and editing, Y.K. and S.I.; visualization, Y.Y. and Q.L.; supervision, Y.K.; project administration, Y.K.; funding acquisition, Y.K. All authors have read and agreed to the published version of the manuscript.

Funding: This research was funded by the Japan Science and Technology Agency (JST) for the CREST (grant number: JPMJCR1423) and CONCERT-Japan (grant number: JPMJSC18C4) programs, and by Japan Society for the Promotion of Science (JSPS), Grant-in-Aid for Scientific Research (B), grant number 19H02513.

Conflicts of Interest: The authors declare no conflict of interest.

\section{References}

1. Davis, M.E. Zeolites from a materials chemistry perspective. Chem. Mater. 2014, 26, 239-245. [CrossRef]

2. Groen, J.C.; Bach, T.; Ziese, U.; Paulaime-van Donk, A.M.; de Jong, K.P.; Moulijn, J.A.; Pérez-Ramírez, J. Creation of hollow zeolite architectures by controlled desilication of Al-zoned ZSM-5 crystals. J. Am. Chem. Soc. 2005, 127, 10792-10793. [CrossRef] [PubMed]

3. Van Speybroeck, V.; Hemelsoet, K.; Joos, L.; Waroquier, M.; Bell, R.G.; Catlow, C.R. Advances in theory and their application within the field of zeolite chemistry. Chem. Soc. Rev. 2015, 44, 7044-7111. [CrossRef] [PubMed]

4. Degnan, T.F., Jr. The implications of the fundamentals of shape selectivity for the development of catalysts for the petroleum and petrochemical industries. J. Catal. 2003, 216, 32-46. [CrossRef]

5. Ruthven, D.M.; Reyes, S.C. Adsorptive separation of light olefins from paraffins. Microporous Mesoporous Mater. 2007, 104, 59-66. [CrossRef]

6. Degnan, T.F., Jr. Applications of zeolites in petroleum refining. Top. Catal. 2000, 13, 349-356. [CrossRef]

7. Camblor, M.A.; Barrett, P.A.; Díaz-Cabañas, M.; Villaescusa, L.A.; Puche, M.; Boix, T.; Pérez, E.; Koller, H. High silica zeolites with three-dimensional systems of large pore channels. Microporous Mesoporous Mater. 2001, 48, 11-22. [CrossRef]

8. Reddy, K.S.N.; Rao, B.S.; Shiralkar, V.P. Alkylation of benzene with isopropanol over zeolite beta. Appl. Catal. A Gen. 1993, 95, 53-63. [CrossRef]

9. Shamshoum, E.S.; Schuler, T.R.; Ghosh, A.K. Aromatic Alkylation Process Employing Steam Modified Zeolite Beta Catalyst. U.S. Patent 5,227,558, 13 July 1993. 
10. Gajda, G.J.; Gajek, R.T. Zeolite Beta and Its Use in Aromatic Alkylation. U.S. Patent 5723710A, 3 March 1998.

11. Wadlinger, R.L.; Kerr, G.T.; Rosinski, E.J. Catalytic Composition of a Crystalline Zeolite. U.S. Patent 3,308,069, 7 March 1967.

12. Corma, A.; Camblor, M.; Esteve, P.; Martinez, A.; Perezpariente, J. Activity of Ti-Beta catalyst for the selective oxidation of alkenes and alkanes. J. Catal. 1994, 145, 151-158. [CrossRef]

13. Corma, A.; Nemeth, L.T.; Renz, M.; Valencia, S. Sn-zeolite beta as a heterogeneous chemoselective catalyst for Baeyer-Villiger oxidations. Nature 2001, 412, 423-425. [CrossRef]

14. Lobo, R.F.; Davis, M.E. CIT-1: A new molecular sieve with intersecting pores bounded by 10-and 12-rings. J. Am. Chem. Soc. 1995, 117, 3766-3779. [CrossRef]

15. Yoshioka, M.; Yokoi, T.; Tatsumi, T. Development of the CON-type aluminosilicate zeolite and its catalytic application for the MTO reaction. ACS Catal. 2015, 5, 4268-4275. [CrossRef]

16. Elangovan, S.P.; Ogura, M.; Davis, M.E.; Okubo, T. SSZ-33: A promising material for use as a hydrocarbon trap. J. Phys. Chem. B 2004, 108, 13059-13061. [CrossRef]

17. Mathew, T.; Elangovan, S.P.; Yokoi, T.; Tatsumi, T.; Ogura, M.; Kubota, Y.; Shimojima, A.; Okubo, T. Synthesis and characterization of aluminium containing CIT-1 and their structure-property relationship to hydrocarbon trap performance. Microporous Mesoporous Mater. 2010, 129, 126-135. [CrossRef]

18. Kubota, H.; Liu, C.; Toyao, T.; Maeno, Z.; Ogura, M.; Nakazawa, N.; Inagaki, S.; Kubota, Y.; Shimizu, K. Formation and Reactions of $\mathrm{NH}_{4} \mathrm{NO}_{3}$ during Transient and Steady-state $\mathrm{NH}_{3}-\mathrm{SCR}$ of $\mathrm{NO}_{\mathrm{x}}$ over H-AFX Zeolites: Spectroscopic and Theoretical Studies. ACS Catal. 2020, 2334-2344. [CrossRef]

19. Nakazawa, N.; Ikeda, T.; Hiyoshi, N.; Yoshida, Y.; Han, Q.; Inagaki, S.; Kubota, Y. A microporous aluminosilicate with 12-, 12-, and 8-ring pores and isolated 8-ring channels. J. Am. Chem. Soc. 2017, 139, 7989-7997. [CrossRef]

20. Database of Zeolite Structures. Available online: http://www.iza-structure.org/databases/ (accessed on 16 March 2020).

21. Nakazawa, N.; Yoshida, Y.; Inagaki, S.; Kubota, Y. Synthesis of novel aluminosilicate YNU-5 and enhancement of the framework thermal stability by post-synthesis treatment. Microporous Mesoporous Mater. 2019, 280, 66-74. [CrossRef]

22. Kawase, R.; Iida, A.; Kubota, Y.; Komura, K.; Sugi, Y.; Oyama, K.; Itoh, H. Hydrothermal synthesis of calcium and boron containing MFI-type zeolites by using organic amine as structure directing agent. Ind. Eng. Chem. Res. 2007, 46, 1091-1098. [CrossRef]

23. Kubota, Y.; Tawada, S.; Nakagawa, K.; Naitoh, C.; Sugimoto, N.; Fukushima, Y.; Hanaoka, T.; Imada, Y.; Sugi, Y. Synthetic investigation of CIT-5 catalyst. Microporous Mesoporous Mater. 2000, 37, 291-301. [CrossRef]

24. Inagaki, S.; Shinoda, S.; Kaneko, Y.; Takechi, K.; Komatsu, R.; Tsuboi, Y.; Yamazaki, H.; Kondo, J.; Kubota, Y. Facile fabrication of ZSM- 5 zeolite catalyst with high durability to coke formation during catalytic cracking of paraffins. ACS Catal. 2013, 3, 74-78. [CrossRef]

25. Inagaki, S.; Tsuboi, Y.; Nishita, Y.; Syahylah, T.; Wakihara, T.; Kubota, Y. Rapid Synthesis of an Aluminum-Rich MSE-Type Zeolite by the Hydrothermal Conversion of an FAU-Type Zeolite. Chem. Eur. J. 2013, 19, 7780-7786. [CrossRef]

26. Maekawa, H.; Kubota, Y.; Sugi, Y. Hydrothermal synthesis of [Al]-SSZ-24 from [Al]-beta zeolite ([Al]-BEA) as precursors. Chem. Lett. 2004, 33, 1126-1127. [CrossRef]

27. Kubota, Y.; Maekawa, H.; Miyata, S.; Tatsumi, T.; Sugi, Y. Hydrothermal synthesis of metallosilicate SSZ-24 from metallosilicate beta as precursors. Microporous Mesoporous Mater. 2007, 101, 115-126. [CrossRef]

28. Ahedi, R.K.; Kubota, Y.; Sugi, Y. Synthesis of [Al]-SSZ-31 molecular sieves using [Al]-beta zeolite ([Al]-BEA) as precursors. Bull. Chem. Soc. Jpn. 2003, 76, 883-890. [CrossRef]

29. Niwa, M.; Katada, N. Measurements of acidic property of zeolites by temperature programmed desorption of ammonia. Catal. Surv. Jpn. 1997, 1, 215-226. [CrossRef]

30. Niwa, M.; Katada, N. New Method for the Temperature-Programmed Desorption (TPD) of Ammonia Experiment for Characterization of Zeolite Acidity: A Review. Chem. Rec. 2013, 13, 432-455. [CrossRef]

31. Park, S.; Watanabe, Y.; Nishita, Y.; Fukuoka, T.; Inagaki, S.; Kubota, Y. Catalytic conversion of dimethyl ether into propylene over MCM-68 zeolite. J. Catal. 2014, 319, 265-273. [CrossRef]

32. Sawa, M.; Niwa, M.; Murakami, Y. Relationship between acid amount and framework aluminum content in mordenite. Zeolite 1990, 10, 532-538. [CrossRef] 
33. Cordero-Lanzac, T.; Ateka, A.; Pérez-Uriarte, P.; Castaño, P.; Aguayo, A.T.; Bilbao, J. Insight into the deactivation and regeneration of HZSM-5 zeolite catalysts in the conversion of dimethyl ether to olefins. Ind. Eng. Chem. Res. 2018, 57, 13689-13702. [CrossRef]

34. Seidel, C.; Jörke, A.; Vollbrecht, B.; Seidel-Morgenstern, A.; Kienle, A. Kinetic modeling of methanol synthesis from renewable resources. Chem. Eng. Sci. 2018, 175, 130-138. [CrossRef]

35. Al-Dughaither, A.S.; de Lasa, H. Neat dimethyl ether conversion to olefins (DTO) over HZSM-5: Effect of $\mathrm{SiO}_{2} / \mathrm{Al}_{2} \mathrm{O}_{3}$ on porosity, surface chemistry, and reactivity. Fuel 2014, 138, 52-64. [CrossRef]

36. Deimund, M.A.; Harrison, L.; Lunn, J.D.; Liu, Y.; Malek, A.; Shayib, R.; Davis, M.E. Effect of heteroatom concentration in SSZ-13 on the methanol-to-olefins reaction. ACS Catal. 2016, 6, 542-550. [CrossRef]

37. Zhu, X.; Liu, S.; Song, Y.; Xu, L. Catalytic cracking of $C_{4}$ alkenes to propene and ethene: Influences of zeolites pore structures and $\mathrm{Si} / \mathrm{Al}_{2}$ ratios. Appl. Catal. A Gen. 2005, 288, 134-142. [CrossRef]

38. Blay, V.; Epelde, E.; Miravalles, R.; Perea, L.A. Converting olefins to propene: Ethene to propene and olefin cracking. Catal. Rev. 2018, 60, 278-335. [CrossRef]

39. Boulens, P.; Pellier, E.; Jeanneau, E.; Reek, J.N.; Olivier-Bourbigou, H.; Breuil, P.A.R. Self-assembled organometallic nickel complexes as catalysts for selective dimerization of ethylene into 1-butene. Organometallics 2015, 34, 1139-1142. [CrossRef]

(C) 2020 by the authors. Licensee MDPI, Basel, Switzerland. This article is an open access article distributed under the terms and conditions of the Creative Commons Attribution (CC BY) license (http://creativecommons.org/licenses/by/4.0/). 